\title{
Knowledge and Attitude about Radiation Effects on Pregnant Women among Medical Students
}

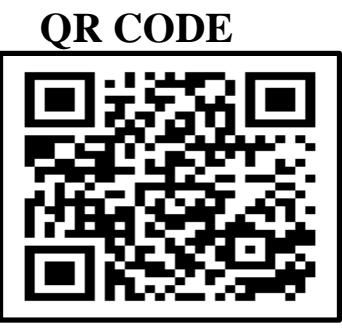

\author{
PREM SHERPA', SANYAM MANDAL², RAKESH PARSI3
}

INTRODUCTION: Radiation and safety aspects while during pregnancy are always a matter of concern. It is required for medical students to learn about the various effects of radiology as ionizing radiation are carrying strong biological effects on pregnant females.

AIM: To assess the awareness level among medical students regarding radiation risks for pregnant women.

MATERIALS AND METHODS: This Questionnaire based cross sectional study was conducted among 250 medical students in one medical institute in India. Questionnaire consisted of knowledge and attitude related questions regarding effects of radiation on pregnancy and collected data was analyzed by using SPSS and descriptive statistics and chi square test was used for further analysis.

RESULTS: In the present study, MBBS students were 60 (24\%) and BDS were $190(76 \%)$. 100\% MBBS students reported that X-rays are destructive to pregnant females in comparison to only $90 \%$ BDS students ( $\mathrm{p}=0.01$ ). Both $75 \% \mathrm{MBBS}$ and $70 \%$ BDS students "strongly agreed" to the fact that "Education and training programmes should be conducted for increased awareness among medical professionals regarding the radiation effects in pregnant females (Non-significant).

CONCLUSION: Although medical students were aware about radiology and pregnancy related effects but still there is room for improvement.

KEYWORDS: Dental, Radiology, X-Rays, Biological Effects

\section{INTRODUCTION}

Ionizing radiations are carrying damaging effects especially biological either directly or indirectly through the production of free radicals. ${ }^{1}$ High-dose ionizing radiations (x-ray) are having mutually deterministic as well as stochastic effects. In contrary to lower doses, radiation hazards are primarily stochastic rather than deterministic. ${ }^{2}$ Nonstochastic or deterministic are those where there is determined dose above which the destructive abuse starts to appear whereas among stochastic effects there is no deterministic dose that could lead to biological damage..$^{1,3}$

In order to avoid these harmful effects of radiations, risk/benefit concept has been developed by the International Commission on Radiological Protection(ICRP) since 1977 which recommends exposures must be reasonable and kept as low as possible for all the patients. Hence, ALARA principle "As Low as Reasonably Achievable" should be kept in mind while during regular work practice. ${ }^{2,4}$

Choosing the most apposite imaging modality and radiation exposure while during the pregnant female is a frequent clinical question and the management of such patients are multifaceted topic. ${ }^{5}$ Pregnant women are commonly anxious and used to be concern about the fetus and various risks or malformations associated with radiation exposure. ${ }^{1,5}$ However, no radiography procedure should be carried out on pregnant women unless there is an absolute necessity. ${ }^{1}$ All techniques for minimizing the absorbed dose should be undertaken and radiographs should be provided with wellcollimated beams in precisely-protected shields. A high- $\mathrm{kVp}$ technique is appropriate in such cases. ${ }^{3}$

Radiation risks all through the pregnancy which is strongly related to the pregnancy stage and the absorbed dose1. Most of the biologic responses to radiation occur during the first two weeks of pregnancy, which is a period when the mother is unaware of her pregnancy, and these responses lead to miscarriage of the fetus. Therefore, there is no concern about congenital abnormalities during the first two weeks of pregnancy. ${ }^{1,5,6}$ But being into medical profession person should be able to know about the radiation safety and best possible methods especially during pregnancy time as radiology is a decisive part of clinical medicine with a strong contribution in clinical care. Although radiology-specific objectives have also been incorporated into medical curriculum in recent years, but still many of the medical students are not much aware about the radiation dosage safety. It has been reported through literature that many dentists post-pone dental treatments to the period after delivery because they do not have sufficient knowledge

(C) Prem Sherpa et al. This is an open access article distributed under the terms of the Creative Commons Attribution License CC-BY-NC 4.0, which permits unrestricted use, distribution and reproduction in any medium, provided the use is not commercial and the original author(s) and source are cited. Submitted on: 24-Nov-2021; Accepted on: 27-Jan-2022 
of the low doses involved in diagnostic dental radiation. ${ }^{7,8,9}$ The delay in treatment might have adverse effects on the mother and the fetus. The aim of the present study was to assess the awareness level among medical students (MBBS and BDS) regarding radiation risks for pregnant women

\section{MATERIALS AND METHOD}

This questionnaire based cross sectional study was conducted a medical college in India (name withheld on request) among 250 medical students of one of the medical institute in India. All of the eligible subjects were included in the study without discrimination. Ethical approval was received from the institutional review board and informed written consent was obtained from all the study participants.

Data was collected by sending questionnaires through email, phones and by distributing personally to the students. The questionnaire consisted of 18 questions about the awareness of the risk of radiation among pregnant women. The questionnaire consisted questions regarding the safe dose for fetus, radiation protection principles, radiation dose on pregnancy termination all of which that result in reduced radiation dose to pregnant women. The collected data were analyzed using SPSS (Statistical Package for Social Sciences) software, version 22.o (SPSS Inc., Chicago, IL, USA) with the help of descriptive statistical tests and chi square test was used and the level of significance was set at $\mathrm{p} \leq 0.05$.

\section{RESULTS}

In this cross-sectional study, the mean age of the subjects was $21.82 \pm 2.78$ years. Among 250 dentists 159 were females and 91 were males whereas MBBS students were 60 ( $24 \%)$ and BDS were $190(76 \%)$. While assessing the knowledge regarding radiation effects on pregnant women among studied subjects, $100 \%$ MBBS students reported that X-rays are destructive to pregnant females in comparison to only 90\% BDS students and the difference was found to be significant $(\mathrm{p}=\mathrm{o} .01)$. Another interesting observation was seen while answering the question "Do you know about safe dosage of radiation?", only $6.67 \%$ of MBBS students reported not knowing it, in comparison to $82.1 \%$ of BDS students who did not know the safe radiation doses $(\mathrm{p}=\mathrm{o.01})$. Responses to other questions on knowledge is depicted in table 1.
Upon accessing the attitude regarding radiation effects on pregnant women (table 2), $1.05 \%$ of BDS students reported Neither agree nor disagree on the question "Do you think so X-rays should be avoided in the pregnancy" ( $\mathrm{p}=\mathbf{0 . 0 0 2}$ ). Both 75\% MBBS and 70\% BDS students "strongly agreed" to the fact that "Education and training programmes should be conducted for increased awareness among medical professionals regarding the radiation effects in pregnant females" and the difference was found to be non-significant.

\section{DISCUSSION}

Cancerous conditions, abortion, fetus mutagenic changes, cataracts, etc are strongly associated with radiation exposure. The radiation effect could be stochastic which can lead to episode of biological hazards. ${ }^{4,5}$ Henceforth, the radiation protection protocol should be followed and medical personnel should be restricted to the ALARA principle concept which keeping radiation exposure "As Low As Reasonably Achievable". ${ }^{4}$

So, a scrupulous knowledge about the biological hazards of X-Rays is required and considering this, in the present study, knowledge of medical students is assessed regarding the effect of radiation among pregnant women. The present studies revealed that majority of the medical students consider $\mathrm{x}$ rays to be harmful. Comparatively it is an elevated percentage especially for the MBBS students compared to the dental students, which could be due to strong course regarding radiology medicine with special emphasizing on biological hazards and different methods of protection. It's been seen through this study $30 \%$ of MBBS and $52.4 \%$ of dental students know that X-rays does not lead to preterm birth and low birth weight at moderate significant level and results are supported by the study by Mortazavi SMJ et al. ${ }^{10}$ that there was no statistical significant differences between the mean weight of new-borns whose mothers had been bare to some common sources of ionizing and non-ionizing radiations and those who were not exposed. However, the findings of the current study cast qualm on preceding reports, which indicated that exposure to ionizing radiation during pregnancy increased the risk of low birth weight.

In the current study, 62.3\% MBBS and $2.63 \%$ dental students were aware of the safe dose of radiation for the fetus and around $44.3 \%$ of dental students and $78.3 \%$ 


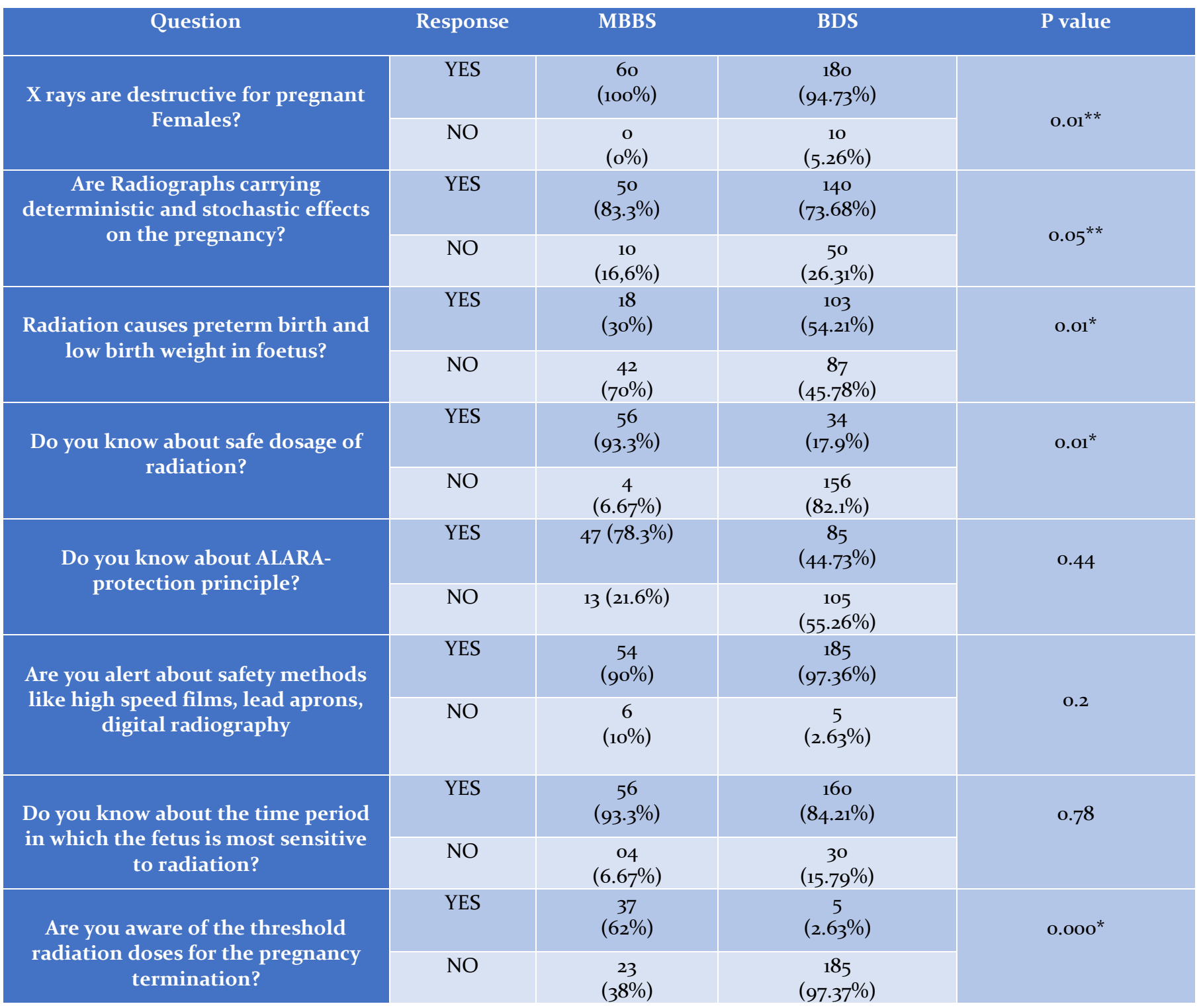

Table 1. Knowledge regarding radiation effects on pregnant women among studied subjects (* statistically significant)

MBBS were aware of the protection principles of ALARA. This means that about $50 \%$ of dental students were unaware of occurrence of radiation biological damage. Even current studies designate that the first semester is the mainly sensitive period during pregnancy, and exposure can lead to definitive defects. ${ }^{3,11}$

It has been seen through the current study that medical students both the MBBS and dental stated that pregnant women should not undergo radiographic procedures unless there is an absolute necessity for it and if procedure should be undertaken; all the necessary precautions should be exercised in order to minimize the radiation dose and effects., ${ }^{3,12}$ It has been also observed that majority of the medical students were having positive attitude towards obligatory accreditation and monitoring by regulatory bodies of the dental and medical clinics using radiography. Although students were having moderate knowledge and positive attitude towards radiation protection related measures still there is room for improvement. Awareness education programs should be planned to increase their knowledge of the safety of radiographic procedures and the use of protective techniques in pregnant women. 


\begin{tabular}{|c|c|c|c|c|c|c|c|}
\hline Question & Course type & $\begin{array}{l}\text { Strongly } \\
\text { Agree }\end{array}$ & Agree & $\begin{array}{l}\text { Neither agree } \\
\text { nor disagree }\end{array}$ & Disagree & $\begin{array}{l}\text { Strongly } \\
\text { Disagree }\end{array}$ & $\begin{array}{c}\mathbf{p} \\
\text { value }\end{array}$ \\
\hline \multirow{2}{*}{$\begin{array}{c}\text { Do you think so X-rays } \\
\text { should be avoided in the } \\
\text { pregnancy }\end{array}$} & MBBS & $\begin{array}{c}7 \\
(11.7 \%)\end{array}$ & $\begin{array}{c}53 \\
(88.3 \%)\end{array}$ & o & o & o & \multirow[t]{2}{*}{$0.002^{*}$} \\
\hline & BDS & $\begin{array}{c}123 \\
(64.73)\end{array}$ & $65(34.21)$ & $2(1.05 \%)$ & o & o & \\
\hline \multirow{2}{*}{$\begin{array}{c}\text { X- rays should only be taken } \\
\text { with proper protection } \\
\text { techniques if highly } \\
\text { necessary }\end{array}$} & MBBS & $\begin{array}{c}54 \\
(90 \%)\end{array}$ & $\begin{array}{c}04 \\
(6.67 \%)\end{array}$ & $\begin{array}{c}02 \\
(3.33 \%)\end{array}$ & o & o & \multirow{2}{*}{$0.000^{*}$} \\
\hline & BDS & $\begin{array}{c}66 \\
(34.74 \%)\end{array}$ & $\begin{array}{c}122 \\
(64.21 \%)\end{array}$ & $\begin{array}{c}02 \\
(1.05 \%)\end{array}$ & o & o & \\
\hline \multirow{2}{*}{$\begin{array}{l}\text { Education and training } \\
\text { programmes should be } \\
\text { conducted for increased } \\
\text { awareness among medical } \\
\text { professionals regarding the } \\
\text { radiation effects in pregnant } \\
\text { females }\end{array}$} & MBBS & $\begin{array}{c}45 \\
(75 \%)\end{array}$ & $\begin{array}{c}15 \\
(25 \%)\end{array}$ & o & o & o & \multirow[t]{2}{*}{0.25} \\
\hline & BDS & $\begin{array}{c}133 \\
(70 \%)\end{array}$ & $\begin{array}{c}55 \\
(28.94 \%)\end{array}$ & $\begin{array}{c}2 \\
(1.06 \%)\end{array}$ & o & o & \\
\hline \multirow{2}{*}{$\begin{array}{l}\text { Do you think so there } \\
\text { should be compulsory } \\
\text { accreditation and } \\
\text { monitoring by regulatory } \\
\text { bodies of the dental and } \\
\text { medical clinics using } \\
\text { radiography }\end{array}$} & MBBS & $\begin{array}{c}40 \\
(66.67 \%)\end{array}$ & $\begin{array}{c}20 \\
(33 \cdot 33 \%)\end{array}$ & o & o & o & \multirow[t]{2}{*}{$0.001^{*}$} \\
\hline & BDS & $\begin{array}{c}70 \\
(36.84 \%)\end{array}$ & $\begin{array}{c}117 \\
(61.57 \%)\end{array}$ & $\begin{array}{c}03 \\
(1.57 \%)\end{array}$ & o & o & \\
\hline
\end{tabular}

Table 2. Attitude regarding radiation effects on pregnant women among studied subjects (* statistically significant)

\section{CONCLUSION}

It has been concluded through the current study that though medical students were having judicious knowledge and optimistic attitude towards radiology medicine but still necessitate strengthening the importance of radiation risks and protection measures among pregnant women in the dental curriculum in India. Even continuing education and training programs should be conducted at customary intervals for stringent observance of different radiographic protection regulation protocols for pregnant women.

\section{REFERENCES}

1. Patil S, Thakur R, Madhu K, Paul ST, Gadicherla P. Oral health coalition: knowledge, attitude, practice behaviours among gynaecologists and dental practitioners. J Int Oral Health. 2013;5(1):8-15.

2. Eskandar OS, Eckford SD, Watkinson T. Safety of diagnostic imaging in pregnancy. Part 1: X-ray, nuclear medicine investigations, computed tomography and contrast media safety of diagnostic imaging in pregnancy. Obstet Gynecol. 2010;12:71-8.

3. Arnout AE, Jafar A. Awareness of biological hazards and radiation protection techniques of dental imaginga questionnaire based cross-sectional study among
Saudi Dental Students. J Dent Health Oral Disord Ther. 2014; 1(1):1-7.

4. Ramanathan S, Ryan J. Radiation awareness among radiology residents, technologists, fellows and staff: where do we stand? Insights Imaging. 2015; 6(1): 133-9. 5. Otake M, Schull WJ. Radiation-related small head sizes among prenatally exposed A-bomb survivors. Int J Radiat Biol. 1993;63:255-70.

6. Mossman KL, Hill LT. Radiation risks in pregnancy. Obstet Gynecol. 1982;60:237-42.

7. McCollough CH, Schueler BA, Atwell TD, et al. Radiation exposure and pregnancy: when should we be concerned? Radiographics. 2007;27:909-17.

8. Kantor ML. Longitudinal trends in the use of individualized radiographic examinations at dental schools in the United States and Canada. J Dent Educ. 2006;70(2):160-8.

9. Lee B-D, Ludlow JB. Attitude of the Korean dentists towards radiation safety and selection criteria. Imaging Sci Dent. 2013;43(3): 179-84.

10. Mortazavi S, Shirazi KR, Mortazavi G. The study of the effects of ionizing and non-ionizing radiations on birth weight of newborns to exposed mothers. J Nat Sc Biol Med. 2013;4(1):213-7. https://doi.org/10.4103/09769668.107293 
11. Parsad M, Gupta R, Pathi B, Singla A, Pandita V, Kumar JK, et al. Imaging More Imagining less: An Insight into Knowledge, Attitude and Practice Regarding Radiation Risk on Pregnant Women among Dentists of Ghaziabad: A Cross Sectional Study. J Clinic Diag Res. 2016; 10(7):20-5.
12. Razi T, Bazvand L, Ghojazadeh M. Diagnostic dental radiation risk during pregnancy: awareness among general dentists in Tabriz. J Dent Res Dent Clin Dent Prospects. 2011; 5(2):67-70. https://doi.org/10.5681/joddd.2011.014

Cite this article as:

Sherpa P, Mandal S, Parsi P. Knowledge and Attitude about Radiation Effects on

Pregnant Women among Medical Students. Int Healthc Res J. 2022;5(10):OR5-OR9.

https://doi.org/10.26440/IHRJ/0510.01499

\section{AUTHOR AFFILIATIONS: $\left({ }^{*}\right.$ Corresponding Author)}

1. MD (Radiology), Consultant Medical Practitioner, Bikaner, Rajasthan, India

2. MD (Internal Medicine), Consultant Medical Practitioner, Kottayam, Kerela, India

3. MBBS, Consultant Medical Practitioner, Indore, Madhya Pradesh, India 